\title{
Syntheses and Co-Fluorescence of Complexes of Eu (III)/Gd (III) with Thienyltrifluoroacetonate, Terephthalic Acid and Phenanthroline
}

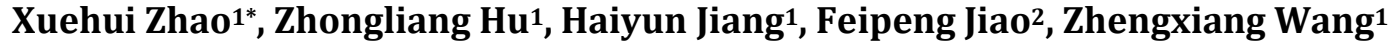 \\ ${ }^{1}$ Key Laboratory of Green Packaging and Application Biological Nanotechnology of Hunan Province, Hunan \\ University of Technology, Zhuzhou, China \\ ${ }^{2}$ College of Chemistry and Chemical Engineering, Central South University, Changsha, China \\ Email: ${ }^{\text {zhaoxuehui2005@126.com }}$
}

Received 9 October 2014; revised 27 November 2014; accepted 13 December 2014

Copyright $@ 2014$ by authors and Scientific Research Publishing Inc.

This work is licensed under the Creative Commons Attribution International License (CC BY). http://creativecommons.org/licenses/by/4.0/

(c) (i) Open Access

\begin{abstract}
A series of complexes of europium (III)/gadolinium (III) with 2-thienyltrifluoroacetonate (HTTA), terephthalic acid (TPA) and phenanthroline (Phen) were synthesized by coprecipitation. The resulting complexes including $\mathrm{Eu}_{2}$ (TPA)(TTA) ${ }_{4} \mathrm{Phen}_{2}, \mathrm{Eu}_{1.4} \mathrm{Gd}_{0.6}(\mathrm{TPA})(\mathrm{TTA})_{4} \mathrm{Phen}_{2}$,

$\mathrm{Eu}_{1.0} \mathrm{Gd}_{1.0}(\mathrm{TPA})(\mathrm{TTA})_{4} \mathrm{Phen}_{2}$ and $\mathrm{Eu}_{0.8} \mathrm{Gd}_{1.2}$ (TPA)(TTA) ${ }_{4} \mathrm{Phen}_{2}$ were characterized by elemental analysis, IR spectroscopy and thermal stability analysis. The results of analysis indicate that the complexes obtained have similar binuclear structure with each other. The thermal stability analysis indicates that the complexes $\mathrm{Eu}_{2}$ (TPA)(TTA) ${ }_{4} \mathrm{Phen}_{2}$ and $\mathrm{Eu}_{1.0} \mathrm{Gd}_{1.0}(\mathrm{TPA})(\mathrm{TTA})_{4} \mathrm{Phen}_{2}$ possess good thermal stability, which melt at $\sim 241^{\circ} \mathrm{C}$ and decompose at $\sim 370^{\circ} \mathrm{C}-430^{\circ} \mathrm{C}$ corresponding to the formation of the complexes. The fluorescence spectra of $\operatorname{Eu}_{2(1-x)} G_{2 x}(T P A)(T T A)_{4} P_{2 h e n}(x=0$ 1) complex powders and their doped silica gels were studied. The co-fluorescence effect of $\mathrm{Gd}^{3+}$ ions in complex powders is different from that of their doped silica gels. The optimum concentration of $\mathrm{Gd}^{3+}$ for complex powders and their doped silica gels is 0.5 and 0.3 (molar fraction), respectively. The co-fluorescence distinction of $\mathrm{Gd}^{3+}$ ions for complex powders and their doped silica gels is preferably interpreted from the proposed binuclear structure together with monomolecular compositions of the complexes for the first time. Both intermolecular energy transfer and intra molecular energy transfer in cross binuclear monomolecular EuGd(TPA)(TTA) ${ }_{4}$ Phen $_{2}$ are thought to be responsible for the co-fluorescence effect of the complex powders; yet only the latter is thought to be responsible for the co-fluorescence effect in silica gels, for the complex molecules in this case are isolated from each other.
\end{abstract}

${ }^{*}$ Corresponding author.

How to cite this paper: Zhao, X.H., Hu, Z.L., Jiang, H.Y., Jiao, F.P. and Wang, Z.X. (2014) Syntheses and Co-Fluorescence of Complexes of Eu (III)/Gd (III) with Thienyltrifluoroacetonate, Terephthalic Acid and Phenanthroline. American Journal of Analytical Chemistry, 5, 1313-1321. http://dx.doi.org/10.4236/ajac.2014.517137 


\section{Keywords}

\section{Co-Fluorescence, Europium, Terephthalic Acid, 2-Thienyltrifluoroacetonate, Silica Gel}

\section{Introduction}

The fluorescence enhancement of the trivalent rare earth complexes still enjoys a growing interest due to their important application in time-resolved fluoroimmunoassays, electro-optical devices and amorphous luminescent materials [1]-[4]. Generally, the fluorescence enhancement can be achieved through ligand sensitization. In this process, ultraviolet light is firstly absorbed by organic Ligands. Then, the absorbed energy is transferred to rare earth ions and makes them send out their characteristic light. Organic ligands have usually a broad absorption band in the region of near ultra-violet. If the energy level of the triplet state of organic ligands matches well with the emission energy level of rare earth ions, the energy transfer of ligands to rare earth ions is very efficient. This will result in the great increase in fluorescence intensity of rare earth ions [5]. For this purpose, various ligands have been used, the more popular ones being the $\beta$-diketones [6]-[8], such as 2-thienyltrifluoroacetonate, benzoylacetone and dibenzoylmethane. The aromatic carboxylic acids as an excellent ligand are also popular [9]-[11], such as trimesic acid, terephthalic acid and pyromellitic acid. The fluorescence of rare earth complexes can also be further enhanced by the use of synergistic agents, such as trioctylphosphine oxide, phenanthroline, organic phosphates and sulphoxides.

Another method to increase the fluorescence of the trivalent rare earth complexes is through the use of certain lanthanide ions such as $\mathrm{La}^{3+}$, $\mathrm{Gd}^{3+}$ and $\mathrm{Tb}^{3+}$ [12]-[15]. In the presence of these ions, the fluorescence enhancement of some rare earth complexes can be obtained. This process is referred to as co-fluorescence, which is extensively studied in the mononuclear complexes of Europiun (III) ions with $\beta$-diketones ligands, such as $\mathrm{Eu}(\mathrm{TTA})_{3} \mathrm{Phen} \mathrm{[12],} \mathrm{Eu}(\mathrm{Dbm})_{3} \mathrm{Phen}[13]$ and $\mathrm{Eu}(\mathrm{TTA})_{3} \mathrm{TPPO}_{2}$. As far as the mononuclear complex is concerned, the co-fluorescence can be found in a micellar environment [16] [17]. In an actual solution, there is no co-fluorescence because the long distance between the chelates makes intermolecular energy transfer impossible. In solids, especially in coprecipitates, the distance between the complex molecules can be short enough to incur an intermolecular energy transfer. However, for the binuclear or polynuclear complexes their co-fluorescence properties are different from those of mononuclear complexes. Therefore, it is very significant to study the cofluorescence effect of the binuclear or polynuclear complexes in solids. Such studies can be helpful in better understanding of the co-fluorescence mechanism.

Recently, synthesis and fluorescent properties of the mononuclear complexes of europium (III) with $\beta$-diketones ligands (e.g. 2-thienyltrifluoroacetonate (HTTA), dibenzoylmethide) and Phenanthroline (Phen) or trioctylphosphine oxide have been shown [12] [13] [18]. However, the studies on synthesis and cofluorescence of complexes of europium (III)/gadolinium (III) with 2-thienyltrifluoroacetonate, terephthalic acid (TPA) and Phenanthroline have not been reported yet.

In this paper, in order to investigate the co-fluorescence properties of binuclear complexes, the bridging ligand TPA is used to link rare earth ions to form the new binuclear complexes $\mathrm{Eu}_{2(1-\mathrm{x})} \mathrm{Gd}_{2 \mathrm{x}}(\mathrm{TPA})(\mathrm{TTA})_{4} \mathrm{Phen}_{2}$ $(\mathrm{x}=0-1)$. And the co-fluorescence mechanism of $\mathrm{Gd}^{3+}$ in complex powders and their doped silica gels is preferably interpreted from the binuclear structure together with monomolecular composition of the complexes for the first time. In addition, IR absorption spectra and thermal stability of the above mentioned complexes were also studied.

\section{Experimental Details}

\subsection{Reagents and Apparatus}

99.99\% $\mathrm{Eu}_{2} \mathrm{O}_{3}$ and 99.98\% $\mathrm{Gd}_{2} \mathrm{O}_{3}$ were purchased from Jiangxi South Rare Earth Metals Institute in China. 2-thienyltrifluoroacetonate (HTTA), terephthalic acid (TPA), Phenanthroline (Phen) and other reagents were all analytical grade and used without further purification.

C, H, N analysis was performed on an American Perkin-Elmer 2400 II CHNSLO elemental analyzer. The percentages of rare earth ions were determined by complexometric titration with EDTA. The infrared spectra 
were measured at room temperature on Nicolet-550 spectrophotometer (American Perkin-Elmer) using $\mathrm{KBr}$ pellets in the spectral range of $4000-400 \mathrm{~cm}^{-1}$. Differential thermoanalysis (DTA) was performed in a SHDT40 thermoanalyticmeter using aluminum crucibles with $\sim 18.40 \mathrm{mg}$ of sample, under dynamic synthetic air atmosphere $\left(40 \mathrm{~mL} \cdot \mathrm{min}^{-1}\right)$ and heating rate of $10^{\circ} \mathrm{C} \cdot \mathrm{min}^{-1}$ in the temperature range of $30^{\circ} \mathrm{C}-600^{\circ} \mathrm{C}$. The thermogravimetric (TG) curves were recorded with a thermobalance model SHDT-40 in the temperature interval of $30^{\circ} \mathrm{C}-600^{\circ} \mathrm{C}$, using platinum aluminum with $\sim 18.0 \mathrm{mg}$ of sample, under dynamic synthetic air atmosphere (40 $\mathrm{mL} \cdot \mathrm{min}^{-1}$ ) and heating rate of $10^{\circ} \mathrm{C} \cdot \mathrm{min}^{-1}$. A Fluorolog FL3-L $\mathrm{L}_{1}$ (American JOBIN YVON) Spectrometer was used to record excitation and emission spectra of the complex powders and their doped silica gels. The bandwidth of monochromators was set at $2.5 \mathrm{~nm}$ for both excitation and emission.

\subsection{Synthesis of Complexes}

The complex $\mathrm{Eu}_{2}(\mathrm{TPA})(\mathrm{TTA})_{4} \mathrm{Phen}_{2}$ was prepared in the following steps. In the first step, standard solution of europium (III) $\left(1.0 \times 10^{-1} \mathrm{~mol} \cdot \mathrm{L}^{-1}\right)$ was prepared by dissolving $\mathrm{Eu}_{2} \mathrm{O}_{3}$ in hot hydrochloric acid, evaporating up to syrup and diluting with ethanol to a desired volume. HTTA, TPA and Phen were dissolved separately in ethanol with molar ratio of 4:1:2. Subsequently $\mathrm{EuCl}_{3}$ and HTTA solutions were mixed with molar ratio of 1:2, adjusting $\mathrm{pH}$ vales to 5.0, stirred and refluxed for 40 min keeping temperature in water-bath. Then according to molar composition of formula $\mathrm{Eu}_{2}(\mathrm{TPA})(\mathrm{TTA})_{4} \mathrm{Phen}_{2}$, Phen and TPA solutions were added dropwise, keeping $\mathrm{pH}$ vales 6.5, stirred and refluxed until the appearance of an orange precipitate. The solid product was filtered, washed and recrystallized in ethanol.

The complexes $\mathrm{Eu}_{2(1-\mathrm{x})} \mathrm{Gd}_{2 \mathrm{x}}(\mathrm{TPA})(\mathrm{TTA})_{4} \mathrm{Phen}_{2}$ were prepared by the similar process as $\mathrm{Eu}_{2}(\mathrm{TPA})(\mathrm{TTA})_{4} \mathrm{Phen}_{2}$, except that the mixture solution of $\mathrm{EuCl}_{3}$ and $\mathrm{GdCl}_{3}$ was used instead of the $\mathrm{EuCl}_{3}$. The products obtained are an orange precipitate.

\subsection{Incorporation of the Complexes into Silica Gels}

Silica gels were prepared by hydrolysis and condensation of tetraethoxysilane $\mathrm{Si}\left(\mathrm{OC}_{2} \mathrm{H}_{5}\right)_{4}(\mathrm{TEOS})$. TEOS and $\mathrm{H}_{2} \mathrm{O}$ were used according to molar ratio of $1: 4.3$ with the proper amount of dimethylformamide (DMF) as solvent. The DMF solution of the complexes was subsequently added to the silica precursor solution ( $\mathrm{n}_{\text {complex }}: \mathrm{n}_{\text {TEOS }}=$ 1:20). Then the mixed solution was refluxed in a $70^{\circ} \mathrm{C}$ water bath until gelation occurred. The resulting gels were dried at $100^{\circ} \mathrm{C}$ for two weeks for measurement purposes.

\section{Result and Discussion}

\subsection{Composition of Complexes}

The rare earth percentages were determined by complexometric titration with EDTA. Analytical data of C, H, N and rare earth ions percentages (found/calculated) for the complex $\mathrm{Eu}_{2}(\mathrm{TPA})(\mathrm{TTA})_{4} \mathrm{Phen}_{2}$ are Eu (III): 17.15/ 17.74; C: 44.76/44.84; H: 2.02/2.10; N: 3.58/3.27; for the complexes $\mathrm{Eu}_{1.4} \mathrm{Gd}_{0.6}(\mathrm{TPA})(\mathrm{TTA})_{4} \mathrm{Phen}_{2}$ are rare earth (III): 17.76/17.90; C: 44.60/44.76; H: 2.05/2.10; N: 3.39/3.27; for the complexes $\mathrm{Eu}_{1.0} \mathrm{Gd}_{1.0}(\mathrm{TPA})(\mathrm{TTA})_{4} \mathrm{Phen}_{2}$ are rare earth (III): 17.81/18.00; C: 44.57/44.70; H: 1.99/2.10; N: 3.45/3.26; and for the complexes

$\mathrm{Eu}_{0.8} \mathrm{Gd}_{1.2}(\mathrm{TPA})(\mathrm{TTA})_{4} \mathrm{Phen}_{2}$ are rare earth (III): 18.01/18.05; C: 44.50/44.67; H: 1.97/2.10; N: 3.37/3.26. The elemental analytical data are consistent with the calculated values of the general formula of the Eu (III) complexes.

\subsection{Characterization of Complexes}

Table 1 shows some results of IR spectra. The presence of carboxylate groups in the Eu (III) complexes was definitely confirmed by both the asymmetric stretching bands at $1552-1558 \mathrm{~cm}^{-1}$ and the symmetric stretching at $1397-1401 \mathrm{~cm}^{-1}$. The separations $\left(\Delta=v_{\text {as }}-v_{\mathrm{s}}\right.$ ) between $v_{\text {as }}$ (coo) peaks and $v_{\mathrm{s}}$ (coo) pears are in the range of $155-159 \mathrm{~cm}^{-1}$ in the Eu (III) complexes, which are attributed to the bidentate chelating, bidentate bridging and tridentate chelating-bridging coordination modes of carboxylate groups with rare earth ions, since the separations $\left(\Delta=v_{\text {as }}-v_{s}\right)$ in the Eu (III) complexes are lower than that in $\operatorname{Na}_{2}$ TPA $\left(\Delta=168 \mathrm{~cm}^{-1}\right)$ [19] [20]. Furthermore, owing to the great steric hindrance of the complexes $\mathrm{Eu}_{2(1-x)} \mathrm{Gd}_{2 \mathrm{x}}(\mathrm{TPA})(\mathrm{TTA})_{4} \mathrm{Phen}_{2}$, the bidentate bridging and tridentate chelating-bridging coordination of carboxylate groups with rare earth ions becomes more difficult than the bidentate chelating coordination does. Thus, the coordination mode of carboxylate groups of 
Table 1. The IR spectra of some complexes, where $\mathrm{L}=(\mathrm{TPA})(\mathrm{TTA})_{4} \mathrm{Phen}_{2}$.

\begin{tabular}{|c|c|c|c|c|c|}
\hline Compounds & $v_{\mathrm{s}}(\mathrm{coo}) / \mathrm{m}^{-1}$ & $v_{\text {as }}(\mathrm{coo}) / \mathrm{cm}^{-1}$ & $\Delta\left(v_{\mathrm{as}}-v_{\mathrm{s}}\right)$ & $v(\mathrm{co}) / \mathrm{cm}^{-1}$ & $v(\mathrm{C}=\mathrm{N}) / \mathrm{cm}^{-1}$ \\
\hline TTA & & & & 1680 & \\
\hline $\mathrm{Na}_{2} \mathrm{TPA}$ & 1395 & 1563 & 168 & & \\
\hline Phen & & & & & 1596 \\
\hline $\mathrm{EuL}$ & 1397 & 1552 & 155 & 1603 & 1562 \\
\hline $\mathrm{Eu}_{1.4} \mathrm{Gd}_{0.6} \mathrm{~L}$ & 1398 & 1557 & 159 & 1604 & 1560 \\
\hline $\mathrm{Eu}_{1.0} \mathrm{Gd}_{1.0} \mathrm{~L}$ & 1399 & 1556 & 157 & 1609 & 1559 \\
\hline $\mathrm{Eu}_{0.8} \mathrm{Gd}_{1.22} \mathrm{~L}$ & 1401 & 1558 & 157 & 1605 & 1556 \\
\hline
\end{tabular}

TPA with rare earth ions is mainly the bidentate chelating coordination mode in the complexes, and the proposed chemical structure of the complexes is binuclear structure. The IR spectra also show a displacement of $v(\mathrm{C}=\mathrm{O})$ stretching from $\sim 1680 \mathrm{~cm}^{-1}$, in free TTA ligand, to $\sim 1605 \mathrm{~cm}^{-1}$ in the complexes, and a displacement of $v(\mathrm{C}=\mathrm{N})$ stretching from $\sim 1596 \mathrm{~cm}^{-1}$, in free Phen ligand, to $\sim 1559 \mathrm{~cm}^{-1}$ in the complexes, indicating that rare earth ions are coordinated by the oxygen or nitrogen atoms [21].

The DTA and TG curves of $\mathrm{Eu}_{2}(\mathrm{TPA})(\mathrm{TTA})_{4} \mathrm{Phen}_{2}$ and $\mathrm{Eu}_{1.0} \mathrm{Gd}_{1.0}(\mathrm{TPA})(\mathrm{TTA})_{4} \mathrm{Phen}_{2}$ are shown in Figure 1 in the temperature range from $50^{\circ} \mathrm{C}$ to $600^{\circ} \mathrm{C}$. It can be seen that the DTA and TG curves of the complex $\mathrm{Eu}_{2}(\mathrm{TPA})(\mathrm{TTA})_{4} \mathrm{Phen}_{2}$ (Figure $1(\mathrm{~A})$ ) present similar profile to that of the complexes

$\mathrm{Eu}_{1.0} \mathrm{Gd}_{1.0}(\mathrm{TPA})(\mathrm{TTA})_{4} \mathrm{Phen}_{2}$ (Figure 1(B)). Both $\mathrm{Eu}_{2}(\mathrm{TPA})(\mathrm{TTA})_{4} \mathrm{Phen}_{2}$ and $\mathrm{Eu}_{1.0} \mathrm{Gd}_{1.0}(\mathrm{TPA})(\mathrm{TTA})_{4} \mathrm{Phen}_{2}$ possess good thermal stability, which melt at $\sim 241^{\circ} \mathrm{C}$ and decompose at $\sim 370^{\circ} \mathrm{C}-430^{\circ} \mathrm{C}$, with no decomposition before the melting point. These indicate that both have similar chemical structure corresponding to the formation of the new complexes. Moreover, in the interval $50^{\circ} \mathrm{C}-200^{\circ} \mathrm{C}$, the TG curves of the complexes do not present any event relative to water loss, which indicates that the new complexes are in anhydrous form. This is corroborated by elemental analysis.

The fluorescence excitation and emission spectra of the solid state complexes were performed in a Fluorolog FL3- $\mathrm{L}_{1}$ Spectrometer.

Figure 2 shows the excitation spectra of the $\mathrm{Eu}_{2}(\mathrm{TPA})(\mathrm{TTA})_{4} \mathrm{Phen}_{2}, \mathrm{Eu}_{1.4} \mathrm{Gd}_{0.6}(\mathrm{TPA})(\mathrm{TTA})_{4} \mathrm{Phen}_{2}$ and $\mathrm{Eu}_{0.8} \mathrm{Gd}_{1.2}$ (TPA)(TTA) ${ }_{4} \mathrm{Phen}_{2}$ complex powders recorded in the spectral range of 220 - $450 \mathrm{~nm}$ by monitoring the emission at the hypersensitive ${ }^{5} \mathrm{D}_{0} \rightarrow{ }^{7} \mathrm{~F}_{2}$ transition. These complex excitation spectra show a strong broad band ranging from 250 to $425 \mathrm{~nm}$ with the optimum excitation wavelength at $382 \mathrm{~nm}$, and they are entirely different from the excitation spectrum of $\mathrm{Eu}^{3+}$ (without the organic ligands) [22]. These indicate that the ligands have transferred the energy absorbed to the $\mathrm{Eu}^{3+}$ ion, leading to the fluorescence enhancement of $\mathrm{Eu}^{3+}$.

The fluorescence emission spectra of the complexes $\mathrm{Eu}_{2(1-x)} \mathrm{Gd}_{2 \mathrm{x}}(\mathrm{TPA})(\mathrm{TTA})_{4} \mathrm{Phen}_{2}(\mathrm{x}=0-1)$ are all similar except the relative intensity. Figure 3 shows only the emission spectra of $\mathrm{Eu}_{2}(\mathrm{TPA})(\mathrm{TTA})_{4} \mathrm{Phen}_{2}$,

$\mathrm{Eu}_{1.4} \mathrm{Gd}_{0.6}(\mathrm{TPA})(\mathrm{TTA})_{4} \mathrm{Phen}_{2}$ and $\mathrm{Eu}_{0.8} \mathrm{Gd}_{1.2}(\mathrm{TPA})(\mathrm{TTA})_{4} \mathrm{Phen}_{2}$ recorded in the range of $560-710 \mathrm{~nm}$ with the optimum excitation wavelength at room temperature. It can be seen that five typical Eu (III) emission bands appear at $\sim 582, \sim 593, \sim 615, \sim 654, \sim 704 \mathrm{~nm}$, corresponding to ${ }^{5} \mathrm{D}_{0} \rightarrow{ }^{7} \mathrm{~F}_{0},{ }^{5} \mathrm{D}_{0} \rightarrow{ }^{7} \mathrm{~F}_{1},{ }^{5} \mathrm{D}_{0} \rightarrow{ }^{7} \mathrm{~F}_{2},{ }^{5} \mathrm{D}_{0} \rightarrow{ }^{7} \mathrm{~F}_{3}$, and ${ }^{5} \mathrm{D}_{0} \rightarrow{ }^{7} \mathrm{~F}_{4}$, respectively. The characteristic emission peaks of $\mathrm{Eu}^{3+}$ ions do not change with the addition of cofluorescence $\mathrm{Gd}^{3+}$ ions. Compared with the powdered complexes, the silica gels doped with these complexes show weaker split lines of the $\mathrm{Eu}^{3+}$ ion. The phenomenon can be accounted for in the following way. For the powdered complexes, $\mathrm{Eu}^{3+}$ ions with surrounding environment of different ligand groups is in a site without a center of inversion, so the emission peaks split into more lines under the ligand field. However, silica gel is a kind of noncrystalline substance with a porous macrostructure. And the complex molecules fixed in the pores are highly ordered. The weaker split lines of $\mathrm{Eu}^{3+}$ are observed because the symmetry of $\mathrm{Eu}^{3+}$ ion in the powder is lower than that in silica gel.

In Figure 3(A), the relative emission intensity of the complex powder of $\mathrm{Eu}_{2}(\mathrm{TPA})(\mathrm{TTA})_{4} \mathrm{Phen}_{2}$ is weaker than that of $\mathrm{Eu}_{0.8} \mathrm{Gd}_{1.2}(\mathrm{TPA})(\mathrm{TTA})_{4} \mathrm{Phen}_{2}$. While for the silica gels doped with these complexes, in Figure 3(B), the reverse is true. But compared with the silica gels doped with $\mathrm{Eu}_{1.4} \mathrm{Gd}_{0.6}(\mathrm{TPA})(\mathrm{TTA})_{4} \mathrm{Phen}_{2}$, the relative emission intensity of the silica gels with $\mathrm{Eu}_{2}(\mathrm{TPA})(\mathrm{TTA})_{4} \mathrm{Phen}_{2}$ remain weaker. The intermolecular energy transfer cannot explain perfectly these changes of the fluorescence intensity. 


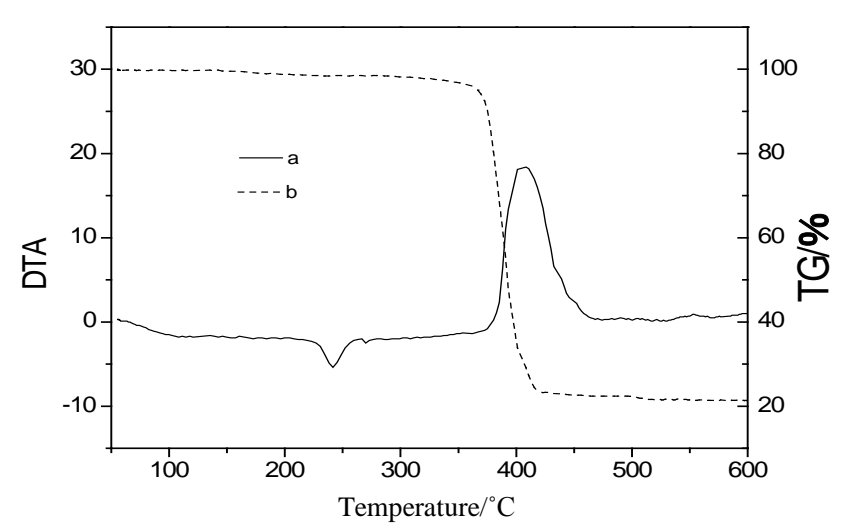

(A)

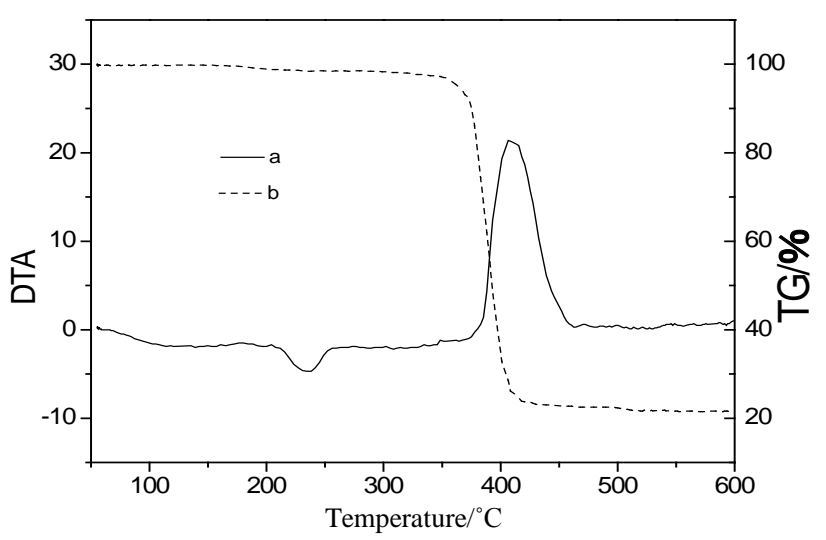

(B)

Figure 1. DTA (a) and TG (b) curves of the complexes $\mathrm{Eu}_{2}$ (TPA)(TTA) ${ }_{4} \mathrm{Phen}_{2}$ (A) and $\mathrm{Eu}_{1.0} \mathrm{Gd}_{1.0}$ (TPA)(TTA) ${ }_{4} \mathrm{Phen}_{2}$ (B).

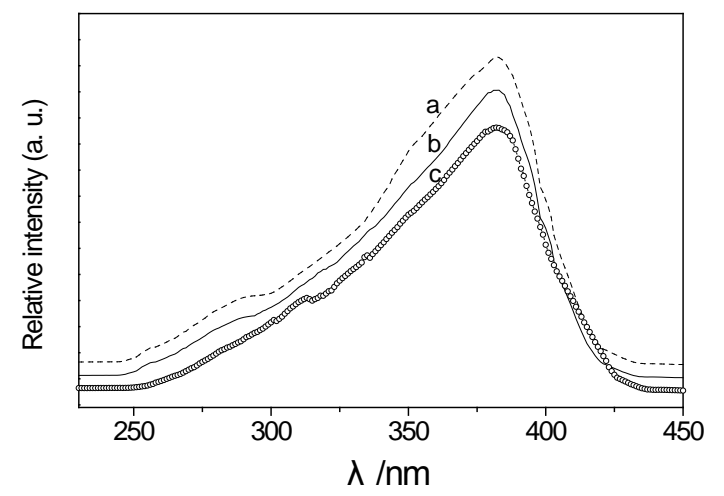

Figure 2. Excitation spectra of the complex powders (a) $\mathrm{Eu}_{0.8} \mathrm{Gd}_{1.2} \mathrm{~L}$, (b) $\mathrm{Eu}_{1.4} \mathrm{Gd}_{0.6} \mathrm{~L}$ and (c) $\mathrm{Eu}_{2} \mathrm{~L}$, where $\mathrm{L}=$ (TPA)(TTA) ${ }_{4}$ Phen $_{2}$.

\subsection{Energy Transfer Processes}

To investigate the co-fluorescence effect of $\mathrm{Gd}^{3+}$ for the complex powders and their doped silica gels, We would assume that co-fluorescence $\mathrm{Gd}^{3+}$ ions have no influence on the fluorescence intensity of $\mathrm{Eu}^{3+}$ in the complexes, the relative emission intensity value $\mathrm{I}_{\text {calc }}$ of the complex powders and their doped silica gels was calculated according to the molar fraction of $\mathrm{Eu}^{3+}$ in different co-fluorescence complexes, and the $\mathrm{I}_{\text {exp }}$ is the relative emission intensity value for experiment, so the ratios of $\mathrm{I}_{\text {exp }}$ and $\mathrm{I}_{\text {calc }}$ can be gotten. The results are also listed in Table 2. 


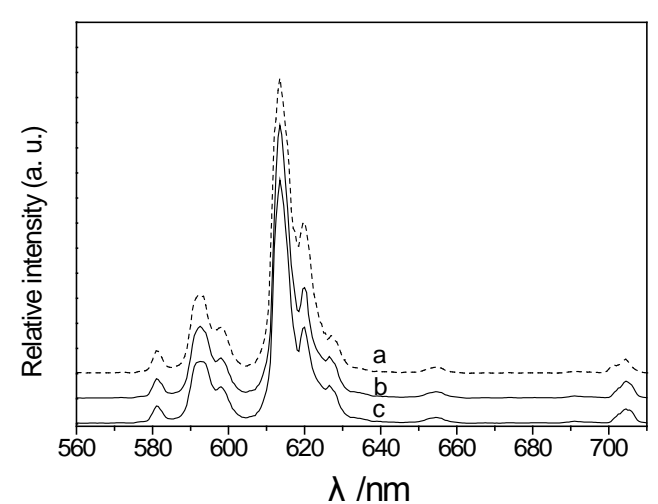

(A)

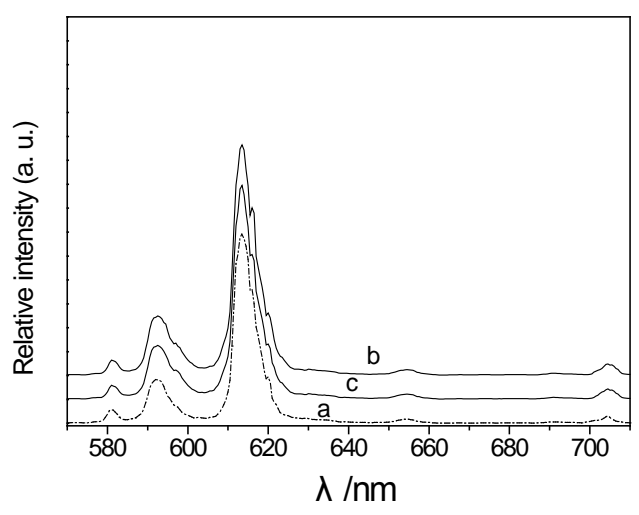

(B)

Figure 3. Emission spectra of the complex powders (A) and their doped silica gels (B), (a) $\mathrm{Eu}_{0.8} \mathrm{Gd}_{1.2} \mathrm{~L}$, (b) $\mathrm{Eu}_{1.4} \mathrm{Gd}_{0.6} \mathrm{~L}$ and (c) $\mathrm{Eu}_{2} \mathrm{~L}$, where $\mathrm{L}=(\mathrm{TPA})(\mathrm{TTA})_{4} \mathrm{Phen}_{2}$.

Table 2. Fluorescence spectra peak positions and relative intensities of the complex powders and their doped silica gels, where $\mathrm{L}=(\mathrm{TPA})(\mathrm{TTA})_{4} \mathrm{Phen}_{2}$.

\begin{tabular}{cccccccccc}
\hline Complexes & $\lambda$ ex/nm & \multicolumn{2}{c}{ complex powders $\lambda$ em/nm (relative intensity) } & \multicolumn{3}{c}{ in silica gel $\lambda$ em/nm (relative intensity) } \\
\hline & & ${ }^{5} \mathrm{D}_{0} \rightarrow{ }^{7} \mathrm{~F}_{2}$ & I calc & Iexp & Iexp $/$ calc & ${ }^{5} \mathrm{D}_{0} \rightarrow{ }^{7} \mathrm{~F}_{2}$ & I calc & Iexp & Iexp/I calc \\
\hline $\mathrm{Gd}_{2} \mathrm{~L}$ & 382 & 614.5 & 0 & 0 & & 614.0 & 0 & 0 & 27 \\
$\mathrm{Eu}_{0.2} \mathrm{Gd}_{1.8} \mathrm{~L}$ & 383 & 614.5 & 10 & 38 & 3.8 & 614.0 & 10 & 27 & 2.7 \\
$\mathrm{Eu}_{0.6} \mathrm{Gd}_{1.4} \mathrm{~L}$ & 383 & 614.5 & 30 & 96 & 3.2 & 614.0 & 30 & 75 & 2.5 \\
$\mathrm{Eu}_{0.8} \mathrm{Gd}_{1.2} \mathrm{~L}$ & 383 & 614.0 & 40 & 121 & 3.0 & 614.0 & 40 & 89 & 2.2 \\
$\mathrm{Eu}_{1.0} \mathrm{Gd}_{1.0} \mathrm{~L}$ & 383 & 614.0 & 50 & 135 & 2.7 & 613.5 & 50 & 98 & 2.0 \\
$\mathrm{Eu}_{1.2} \mathrm{Gd}_{0.8} \mathrm{~L}$ & 382 & 614.0 & 60 & 128 & 2.1 & 613.5 & 60 & 102 & 1.7 \\
$\mathrm{Eu}_{1.4} \mathrm{Gd}_{0.6} \mathrm{~L}$ & 382 & 614.0 & 70 & 112 & 1.6 & 613.5 & 70 & 105 & 1.5 \\
$\mathrm{Eu}_{1.6} \mathrm{Gd}_{0.4} \mathrm{~L}$ & 382 & 614.0 & 80 & 107 & 1.3 & 613.5 & 80 & 103 & 1.3 \\
$\mathrm{Eu}_{1.8} \mathrm{Gd}_{0.2} \mathrm{~L}$ & 381 & 614.0 & 90 & 102 & 1.1 & 613.5 & 90 & 101 & 1.1 \\
$\mathrm{Eu}_{2} \mathrm{~L}$ & 382 & 613.5 & 100 & 100 & 1.0 & 613.5 & 100 & 100 & 1.0 \\
\hline
\end{tabular}

As is well known that the energy transfer for the complexes from the ligand to the lanthanide ions can take place via intra molecular energy transfer mode, and the energy transfer can also take place via intermolecular transfer mode. In this study, we think that the co-fluorescence distinction of $\mathrm{Gd}^{3+}$ ions for complex powders and their doped silica gels can be preferably interpreted from the proposed binuclear structure together with monomolecular compositions of the complexes. Since the coordination mode of carboxylate groups of TPA with rare earth ions is mainly the bidentate chelating coordination mode in the complexes. The proposed binuclear structure may be given in Schemes 1(a)-(c). For a certain $x$ value in $\mathrm{Eu}_{2(1-x)} \mathrm{Gd}_{2 \mathrm{x}}(\mathrm{TPA})(\mathrm{TTA})_{4} \mathrm{Phen}_{2}$, the complex powders were prepared by coprecipitation, so the complexes are composed of monomolecular

EuGd(TPA)(TTA) $)_{4} \mathrm{Phen}_{2}, \mathrm{Eu}_{2}(\mathrm{TPA})(\mathrm{TTA})_{4} \mathrm{Phen}_{2}$ and $\mathrm{Gd}_{2}(\mathrm{TPA})(\mathrm{TTA})_{4} \mathrm{Phen}_{2}$. In addition, the chemical structure of the mononuclear complex Eu(TTA) $)_{3}$ Phen is also given in Scheme 1(d) [8].

Figure 4 shows the relationship between the percentages of every monomolecular compositions and the content of $\mathrm{Gd}^{3+}$ ions in the complexes. It can be seen from Figure 4 firstly, that with the increase of $\mathrm{x}$ value, i.e., the contents of $\mathrm{Gd}^{3+}$ ions, the percentages of monomolecular EuGd(TPA)(TTA) ${ }_{4} \mathrm{Phen}_{2}$ and $\mathrm{Gd}_{2}(\mathrm{TPA})(\mathrm{TTA})_{4} \mathrm{Phen}_{2}$ increase. Since energy can only be transferred from a molecule to other molecules at short distances, and the complex powders were prepared by coprecipitation, the short distance between $\mathrm{Gd}_{2}(\mathrm{TPA})(\mathrm{TTA})_{4} \mathrm{Phen}_{2}$ molecules and $\mathrm{Eu}_{2}(\mathrm{TPA})(\mathrm{TTA})_{4} \mathrm{Phen}_{2}$ molecules in the coprecipitate makes the intermolecular effective energy transfer be possible. In addition, intra molecular energy transfer in cross binuclear monomolecular EuGd(TPA)(TTA) ${ }_{4} \mathrm{Phen}_{2}$ increases. They result in the increase of the emission intensity of the complex powders. When $x$ value is 0.5 , the percentage of monomolecular $\operatorname{EuGd}(\mathrm{TPA})(\mathrm{TTA})_{4} \mathrm{Phen}_{2}$ reaches maximum, the intra 


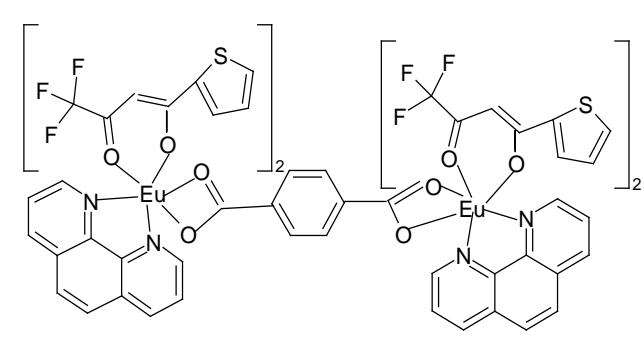

(a)

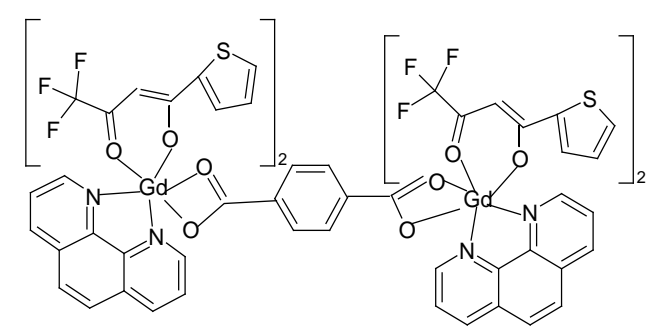

(c)

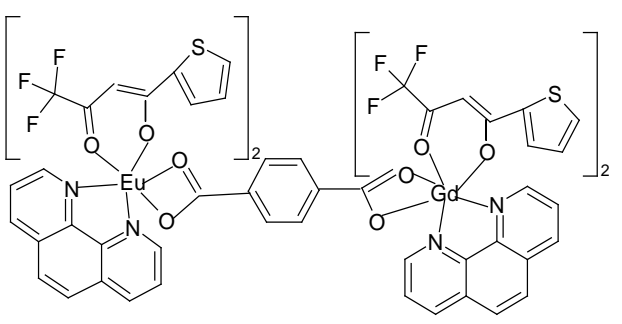

(b)

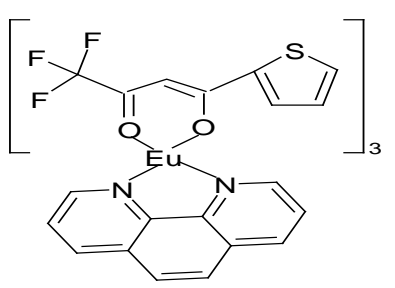

(d)

Scheme 1. Chemical structures of the monomolecular $\mathrm{Eu}_{2} \mathrm{~L}$ (a), EuGdL (b), $\mathrm{Gd}_{2} \mathrm{~L}$ (c) and Eu(TTA) ${ }_{3}$ Phen (d), where $\mathrm{L}=(\mathrm{TPA})(\mathrm{TTA})_{4} \mathrm{Phen}_{2}$.

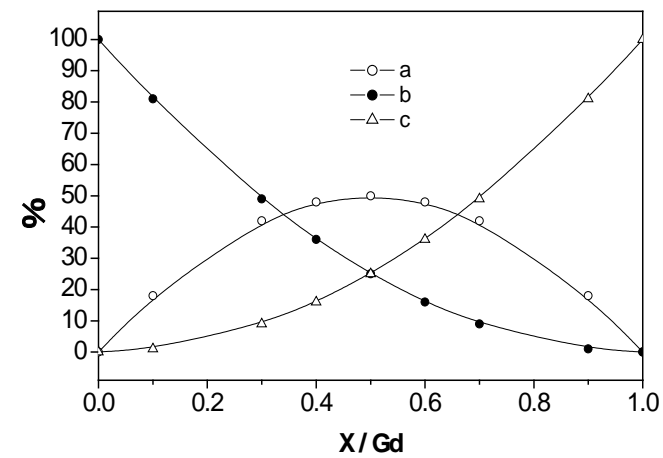

Figure 4. The relationship between the percentages of monomolecular EuGdL (a), $\mathrm{Eu}_{2} \mathrm{~L}$ (b) and $\mathrm{Gd}_{2} \mathrm{~L}$ (c) and the content of $\mathrm{Gd}^{3+}$ ions in the complexes., where $\mathrm{L}=(\mathrm{TPA})(\mathrm{TTA})_{4} \mathrm{Phen}_{2}$.

molecular energy transfer reaches also maximum. Then with a further increase of $\mathrm{x}$ values the intra molecular energy transfer decreases, on the other hand, intermolecular energy transfer is thought to be concerned with the molar ratios of $\mathrm{Eu}_{2}(\mathrm{TPA})(\mathrm{TTA})_{4} \mathrm{Phen}_{2}$ and $\mathrm{Gd}_{2}(\mathrm{TPA})(\mathrm{TTA})_{4} \mathrm{Phen}_{2}$. So the optimum concentration of $\mathrm{Gd}^{3+}$ in the complex powders $\mathrm{Eu}_{2(1-x)} \mathrm{Gd}_{2 \mathrm{x}}(\mathrm{TPA})(\mathrm{TTA})_{4} \mathrm{Phen}_{2}$ is $\sim 0.5$ (molar fraction).

In the silica gel doped with these complexes, the complex molecules are trapped in the pores and isolated from each other. The long distance between complex molecules in the silica gel makes the intermolecular energy transfer impossible. Yet intra molecular energy transfer in cross binuclear monomolecular

EuGd(TPA)(TTA $)_{4} \mathrm{Phen}_{2}$ is not affect by silica gel. So with the increase of the contents of $\mathrm{Gd}^{3+}$ ions, the percentage of the EuGd(TPA)(TTA) ${ }_{4} \mathrm{Phen}_{2}$ increases, the fluorescence intensity of the silica gel doped with these complexes increases. But when the contents of $\mathrm{Gd}^{3+}$ ions attain to certain value, because of the decrease of $\mathrm{Eu}_{2}(\mathrm{TPA})(\mathrm{TTA})_{4} \mathrm{Phen}_{2}$, the fluorescence intensity of the silica gel doped with these complexes decrease. The optimum concentration of $\mathrm{Gd}^{3+}$ in silica gel doped is $\sim 0.3$ (molar fraction). These interpretations from the binuclear structure together with monomolecular composition of the complexes are consistent with the results of the experiment. 


\section{Conclusions}

A series of complexes of europium (III)/gadolinium (III) with 2-thienyltrifluoroacetonate, terephthalic acid and Phenanthroline, showing strong red fluorescence and good thermal stability have been synthesized. Compositions of these complexes are revealed to be $\mathrm{Eu}_{2(1-x)} \mathrm{Gd}_{2 x}(\mathrm{TPA})(\mathrm{TTA})_{4} \mathrm{Phen}_{2}$.

The cofluorescence properties and the mixed complexes $\mathrm{Eu}_{2(1-\mathrm{x})} \mathrm{Gd}_{2 \mathrm{x}}(\mathrm{TPA})(\mathrm{TTA})_{4} \mathrm{Phen}_{2}(\mathrm{x}=0-1)$ are thought to be, for a certain $x$ value in $\mathrm{Eu}_{2(1-\mathrm{x})} \mathrm{Gd}_{2 \mathrm{x}}(\mathrm{TPA})(\mathrm{TTA})_{4} \mathrm{Phen}_{2}$, composed of EuGd(TPA)(TTA) ${ }_{4} \mathrm{Phen}_{2}$, $\mathrm{Eu}_{2}(\mathrm{TPA})(\mathrm{TTA})_{4} \mathrm{Phen}_{2}$ and $\mathrm{Gd}_{2}(\mathrm{TPA})(\mathrm{TTA})_{4} \mathrm{Phen}_{2}$. The fluorescence enhancement of the Eu (III) complexes is observed by the addition of relative cheap $\mathrm{Gd}^{3+}$ ions. The optimum concentration of $\mathrm{Gd}^{3+}$ is 0.5 (molar fraction). The mechanism of the fluorescence enhancement is preferably interpreted from the proposed binuclear structure together with the percentages of every chemical composition in the Eu (III) complexes. Both intermolecular energy transfer mode and intra molecular energy transfer mode are thought to be responsible for the fluorescence enhancement of the complex powders; yet only intra molecular energy transfer is thought to be responsible for the fluorescence enhancement the silica gels doped with these complexes, for the complex molecules are isolated from each other in this case. Both intermolecular energy transfer between monomolecular

$\mathrm{Gd}_{2}$ (TPA)(TTA) ${ }_{4} \mathrm{Phen}_{2}$ and monomolecular $\mathrm{Eu}_{2}(\mathrm{TPA})(\mathrm{TTA})_{4} \mathrm{Phen}_{2}$ and intra molecular energy transfer in cross binuclear monomolecular EuGd(TPA)(TTA) ${ }_{4} \mathrm{Phen}_{2}$ are thought to be responsible for the co-fluorescence of the complex powders; yet only intra molecular energy transfer in cross binuclear monomolecular

EuGd(TPA)(TTA) ${ }_{4}$ Phen $_{2}$ is thought to be responsible for the co-fluorescence in silica gels, for the complex molecules in this case are isolated from each other.

\section{Acknowledgements}

The authors acknowledge the financial supports from the Chinese National Nature Science Foundation (No. 21276070, 21376069).

\section{References}

[1] Richardson, F.S. (1982) Terbium(III) and Europium(III) ions Ions as Luminescent Probes and Stains for Biomolecular System. Chemical Reviews, 82, 541-552. http://dx.doi.org/10.1021/cr00051a004

[2] Wang, Z.M. (2000) Advance in Study of Light Transform Farm Film Doped with Rare Earth in China. Chinese Rare Earths, 21, 55-59.

[3] Li, B., Ma, D., Zhang, H.J., et al. (1998) Electroluminescence Devices Based on Monohexadecyl Phthalate Terbium. Thin Solid Films, 325, 259-263. http://dx.doi.org/10.1016/S0040-6090(98)00506-9

[4] Liu, H.G., Seongtae, P., Kiwan, J., et al. (2004) Influence of Ligands on the Photoluminescent Properties of Eu ${ }^{3+}$ in Europium $\beta$-Diketonate/PMMA-Doped Systems. Journal of Luminescence, 106, 47-55. http://dx.doi.org/10.1016/S0022-2313(03)00133-9

[5] Andrzej, M.K., Stefan, L., Zbingniew, H., et al. (2000) Improvement of Emission Intensity in Luminescent Materials Based on the Antenna Effect. Journal of Alloys and Compounds, 300, 55-60.

[6] Yang, J.H., Zhu, G.Y. and Wu, B. (1987) Enhanced Luminescence of the Europium/Terbium/Thenoyltrifluoroacetone/ 1,10-Phenanthroline/Surfactant System and Its Analytical Application. Analytica Chimica Acta, 198, 287-291. http://dx.doi.org/10.1016/S0003-2670(00)85030-8

[7] Zhang, R.J. and Yang, K.Z. (2000) Fluorescence Lifetime and Energy Transfer of Rare Earth $\beta$-Diketone Complexes in Organized Molecular Films. Thin Solid Films, 363, 275-278. http://dx.doi.org/10.1016/S0040-6090(99)01004-4

[8] Zhang, R.J., Liu, H.G., Zhang, C.R., et al. (1997) Influence of Several Compounds on the Fluorescence of Rare Earth Complexes Eu(TTA) $)_{3}$ Phen and Sm(TTA) ${ }_{3}$ Phen in LB Films. Thin Solid Films, 302, 223-230. http://dx.doi.org/10.1016/S0040-6090(96)09562-4

[9] Paniqrahi, B.S., Peter, S. and Viswanathan, K.S. (1997) Cofluorescence of $\mathrm{Eu}^{3+}$ in Complexes of Aromatic Carboxylic Acid. Spectrochimica Acta Part A, 53, 2579-2585. http://dx.doi.org/10.1016/S1386-1425(97)00190-X

[10] Maji, S. and Viswanathan, K.S. (2008) Ligand-Sensitized Fluorescence of $\mathrm{Eu}^{3+}$ Using Naphthalene Carboxylic Acids as Ligands. Journal of Luminescence, 128, 1255-1261. http://dx.doi.org/10.1016/j.jlumin.2007.12.002

[11] Zhao, G.H., Zhao, S.G., Gao, J.Z. and Kang, J.W. (1997) Sensitivity and Stability Induced by Cyclodextrin in the Fluorescence Analysis of Terbium(III) Ions Using Trimesic Acid. Bulletin des Societes Chimiques Belges, 106, 197-203.

[12] Wang, Z.X., Shu, W.Y., Zhou, Z.C., Liu, Y.N. and Chen, H. (2003) Fluorescence Properties and Application of Doping Complexes $\mathrm{Eu}_{1-\mathrm{x}} \mathrm{L}_{\mathrm{x}}(\mathrm{TTA})_{3}$ Phen as Light Conversion Agents. Journal of Central South University of Technology, 
10, 342-346. http://dx.doi.org/10.1007/s11771-003-0036-4

[13] Yang, J.H., Ren, X.Z., Zhou, H.B. and Shi, R.P. (1990) Enhanced Luminescence of the Europium(III)-Dibenzoylmethane-Ammonia-Acetone System and Its Analytical Application to the Determination of Europium. Analyst, 115, 15051508. http://dx.doi.org/10.1039/an9901501505

[14] Li, W.L., Yu, G. and Huang, S.H. (1993) Enhancement Effects of Y(III)ion on Tb(III) Fluorescence in Tb(III)-Y(III)Benzoic Acide Complexes. Journal Alloys and Compounds, 194, 19-22. http://dx.doi.org/10.1016/0925-8388(93)90639-5

[15] Panigrahi, B.S. (1999) Fluorescence and Cofluorescence Enhancement of $\mathrm{Tb}^{3+}$ and $\mathrm{Eu}^{3+}$ Using Phenyl Phosphonic and Phenyl Phosphinic Acida as Ligands. Journal of Luminesence, 82, 121-127. http://dx.doi.org/10.1016/S0022-2313(99)00037-X

[16] Zhao, G.H. and Zhao, J. (2003) Spectrofluorimtric Determination of Terbium(III) by Fluorescence Enhancement System of $\mathrm{Tb}^{3+}$-TPA-TritonX-100 by $\mathrm{La}^{3+}$. Rare Metals, 22, 112-116.

[17] Yang, J.H., Zhu, G.Y. and Wang, H. (1989) Application of the Columinescence Effect of Rare Earth: Simulataneous Determination of Trace Amounts of Samarium and Europium in Solution. Analyst, 114, 1417-1419. http://dx.doi.org/10.1039/an9891401417

[18] Fu, Y.J., Wong, T.K.S., Yan, Y.K. and Hu, X. (2003) Syntheses, Structures and Luminescent Properties of Sm (III) and Eu (III) Chelates for Organic Electroluminescent Device Applications. Journal of Alloys and Compounds, 358, 235244. http://dx.doi.org/10.1016/S0925-8388(03)00047-1

[19] Deacon, G.B. and Philips, R.J. (1980) Relationships between the Carbon-Oxygen Stretching Frequencies of Carboxylato Complexes and the Type of Carboxylate Coordination. Coordination Chemistry Reviews, 33, 227-250. http://dx.doi.org/10.1016/S0010-8545(00)80455-5

[20] Taylor, M.D., Carter, C.P. and Wynter, C.I. (1968) The Infrared Spectra and Structure of the Rare Earth Benzoates. Journal of Inorganic and Nuclear Chemistry, 30, 1503-1511. http://dx.doi.org/10.1016/0022-1902(68)80290-8

[21] Malta, O.L., Coutodos, S.M.A., Thompson, L.C. and Ito, N.K. (1996) Intensity Parameters of 4f-4f Transitions in the Eu(dipivaloylmethanate) $)_{3}$ 1,10-phenanthroline Complex. Journal of Luminescence, 69, 77-84. http://dx.doi.org/10.1016/0022-2313(96)00084-1

[22] Panigrahi, B.S., Peter, S., Viswanathan, K.S. and Mathews, C.K. (1993) Fluorescence Enhancement and Cofluorescence in Complexes of Terbium, Dysprosium and Europium with Trimesic Acid. Analytica Chimica Acta, 282, 117124. http://dx.doi.org/10.1016/0003-2670(93)80359-S 
Scientific Research Publishing (SCIRP) is one of the largest Open Access journal publishers. It is currently publishing more than 200 open access, online, peer-reviewed journals covering a wide range of academic disciplines. SCIRP serves the worldwide academic communities and contributes to the progress and application of science with its publication.

Other selected journals from SCIRP are listed as below. Submit your manuscript to us via either submit@scirp.org or Online Submission Portal.
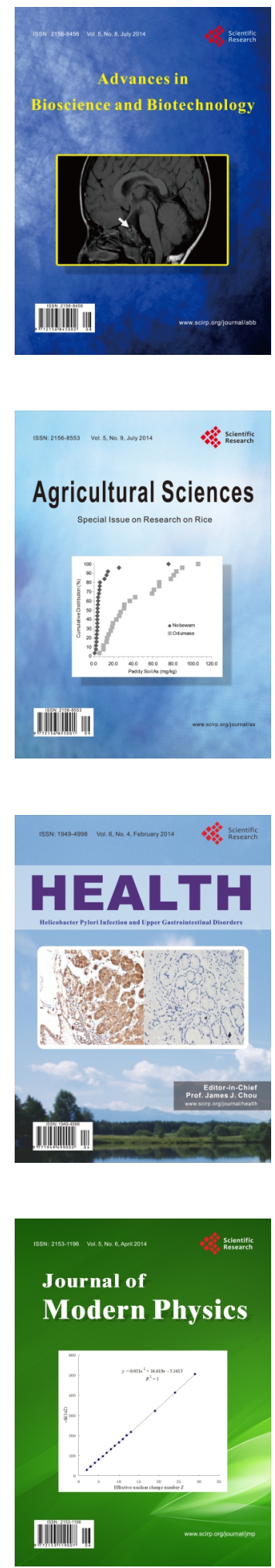
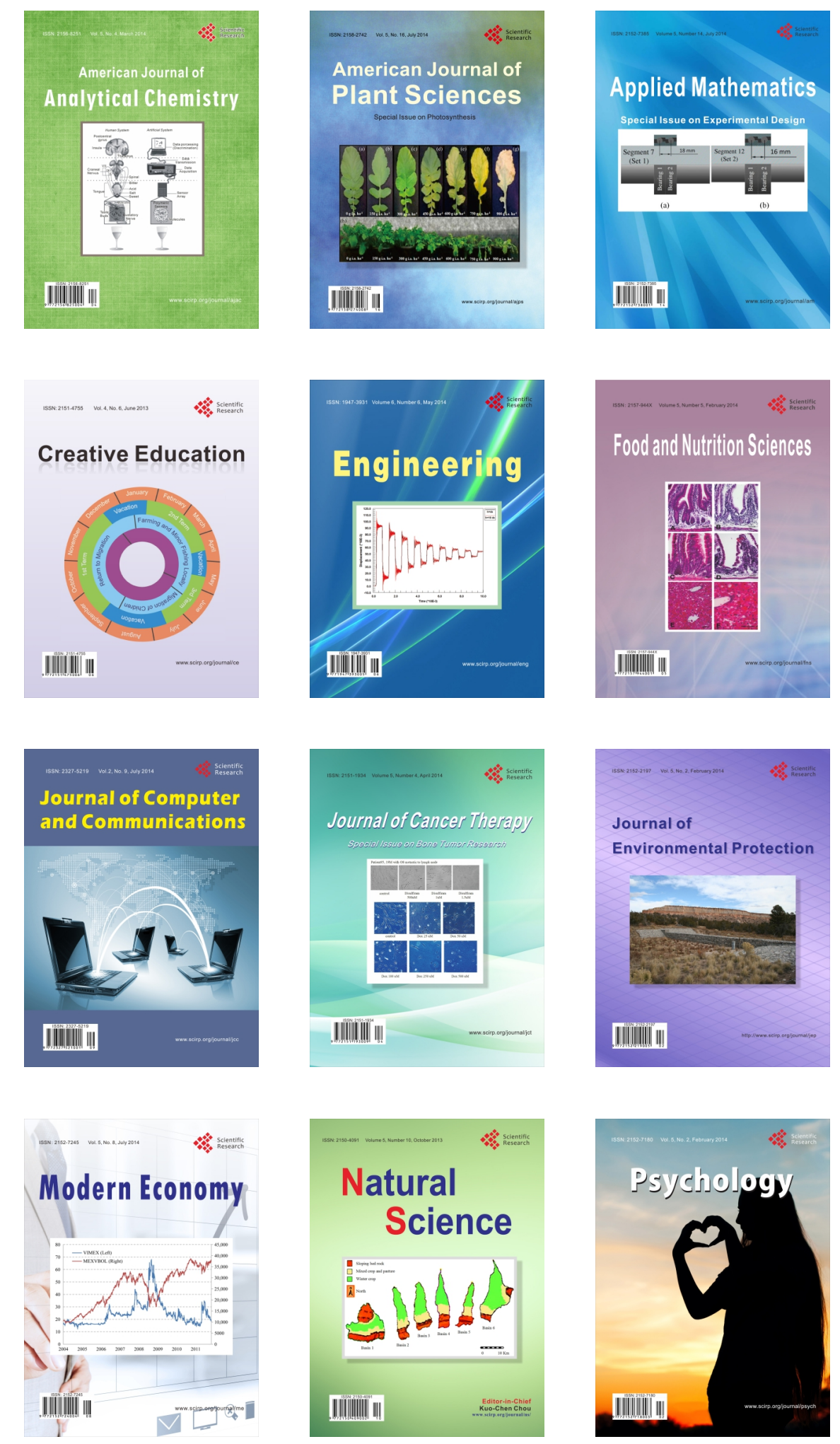